\title{
¿Poder o gratuidad? Aproximación sistémica para comunicar las relaciones mujer-varón
}

\section{Power or gratuity? A systemic approach to communicating woman-male relationships}

\author{
Consuelo Martínez Priego y María Graciela Crespo Ponce ${ }^{1}$ \\ Recibido: 30-05-2017 - Aceptado: 04-08-2017 \\ DOI: https://doi.org/10.26441/RC16.2-2017-A5
}

\begin{abstract}
RESUMEN: Es habitual que los mensajes en medios de comunicación muestren a la familia desde la crisis por la que atraviesa esta institución. Se la concibe con frecuencia, no como el lugar donde la persona es querida por sí misma, sino desde las «luchas de poder» entre sus miembros, especialmente entre la mujer y el varón. Con el método documental -estudio bibliográfico- del análisis conceptual, se busca clarificar algunos elementos esenciales de las relaciones que se dan dentro de la familia, a fin de contribuir a una mejor comunicación de la realidad familiar, en concreto, de la relación mujer-varón. Desde la propuesta metódica sistémica -no analítica- de Leonardo Polo, se propone que son tres los rasgos propios de esta relación -reciprocidad, complementariedad, co-responsabilidad-y que han de estudiarse en su mutua conexión interna para comprender el dinamismo intrafamiliar. De este modo podrá comunicarse su realidad de modo eficaz.
\end{abstract}

Palabras clave: familia, reciprocidad, complementariedad, co-responsabilidad, comunicación.

\begin{abstract}
It is common for media messages to show the family since the crisis that this institution is experiencing. It is often conceived not as the place where the person is loved on his own, but as the "power struggles" between his members, especially between woman and man. With the documentary method - bibliographic study - of the conceptual analysis, this paper seeks to clarify some essential elements of the relationships within the family -in order to contribute to a better communication of the family realityspecifically those related to woman and man. From the systemic -non-analytical- methodical proposal of Leonardo Polo, it is proposed that there are three characteristics of this relationship -reciprocity, complementarity, co-responsibility- that have to be studied in their mutual internal connection to understand intrafamily dynamism. In this way it is possible to communicate effectively its reality.
\end{abstract}

Key words: family, reciprocity, complementarity, co-responsibility, communications.

1 Consuelo Martínez Priego es Doctora en Psicología por la Universidad Complutense de Madrid y Doctora en Filosofía por la Universidad de Navarra. Imparte asignaturas Psicología de la Motivación y de la Emoción; Bases Antropológicas y Sociológicas de la Conducta en el Centro Universitario Villanueva de la Universidad Complutense de Madrid, España. Es investigadora en la Escuela de Pedagogía de la Universidad Panamericana, México. mcmartine@up.edu.mx, http://orcid.org/0000-0001-8479-8790

María Graciela Crespo Ponce es Doctora en Teología y Doctora en Educación por la Universidad de Navarra. Imparte asignaturas Persona y Sociedad y Antropología Teológica en las Facultades de Comunicación y Empresas de la Universidad de Piura. Es investigadora en la Facultad de Humanidades de la Universidad de Piura. mariag.crespo@udep.pe 


\section{Introducción}

La temática familiar es recurrente en los medios de comunicación social. Medios escritos y audiovisuales así como las redes sociales incluyen en sus espacios contenidos relevantes dedicados a la familia. Además, asistimos al hecho de que grandes audiencias se muestran interesadas en series narrativas referidas a la familia. Baste referirnos a las series Mad Men, Breaking Bad, Modern Family, Cuéntame cómo pasó o Downton Abbey. Todas ellas ofrecen visiones distintas de un tema común: la familia.

Por otro lado, familia y crisis parecen ser términos correlativos en nuestro entorno mediático. Que la institución familiar atraviesa una situación de crisis es un lugar común; sin embargo, entendemos que la realidad familiar puede quedar oculta bajo mensajes que solo muestran esa dimensión.

Ya que para comunicar una realidad se requiere comprensión suficiente de la misma, el objetivo de este estudio es clarificar algunos rasgos distintivos de la relación varón-mujer en el seno de la familia en orden a facilitar la comunicación de la realidad familiar. Es decir, poner el acento en los ejes conceptuales que podrían formar parte de los argumentos, imágenes, tipos etc. que se muestran en los medios de comunicación, precisamente para superar las barreras ante las que se encuentra una -no la única- de las notas esenciales de la institución familiar: el estar formada por un varón y una mujer «armónicamente» relacionados.
Evidentemente, profundizar en esta característica esencial no solo arroja luz para la comunicación, sino que ayuda a comprender algo que afecta a la vida familiar misma y posee consecuencias reales en todos los órdenes del vivir humano: la especificidad de la aportación masculina y femenina y, con ello, la relación armónica o de confrontación que produce, tiene manifestaciones en el ámbito social, político y cultural.

\section{Método de estudio}

Para alcanzar el objetivo propuesto el método elegido, acorde al objetivo y perspectiva propuesta, será dual: estudio de bibliografía relevante -no exhaustiva- y análisis conceptual de los hallazgos fundamentales. No se expondrá el proceso de selección de textos, sino su resultado en orden a la clarificación de la temática propuesta. Así, se analizan, en primer lugar, algunas perspectivas que pueden adoptarse en el estudio de la comunicación de una realidad, para pasar después al análisis de «lo comunicado», en nuestro caso la familia; más concretamente, la relación mujer-varón. De este modo, nuestra exposición se centrará directamente en los resultados de estudio, obviando el proceso previo en razón de la extensión prevista.

\section{Comunicar la realidad familiar: lo comunicado}

En el contexto de la comunicación y la educación -la educación es acción comunicativa en uno de sus niveles más altos y eficaces- Emilio Redondo señala 
que la comunicación puede entenderse como:

...la relación real establecida entre dos -o más- seres, en virtud de la cual uno de ellos participa del otro o ambos participan entre sí; o también: relación real establecida entre dos seres en virtud de la cual se ponen en contacto, y uno de ellos -o amboshace donación de algo a otro [...]. La comunicación no puede definirse sin acudir al concepto de participación, el cual expresa ese hacer extensivo algo a otro, que es constitutivo esencial de la comunicación (Redondo, 1999: 178).

La comunicación implica la participación de algo, la tenencia común de alguna realidad, algo tenido que se comprende, un significado compartido, donación que no implica pérdida para el que dona -de ahí el carácter inmaterial de lo participado-. Vistas así las cosas, la comunicación de una realidad puede darse si se «entiende» la realidad misma: si ésta es tenida por el comunicador, si se posee una comprensión tal que sean posibles tanto los mensajes cortos -estamos en la era de los 140 caracteres- como las narraciones. Comunicar, en el siglo XXI, es contar historias (Vilanova, 2012).

Para reflexionar sobre la comunicación de la realidad familiar, el acento puede ponerse en «lo comunicado», no tanto en el «modo de ser comunicado». Entendemos que es necesario atender a la dimensión objetiva -lo comunicadoy a la dimensión subjetiva de la comunicación -a quién se comunica, la consideración del otro como un «tú» activo- (Paz García y Brussino, 2015), así como al medio, recursos y estilo narrativo específico en cada caso; pero puesto que no todo es abordable simultáneamente, este artículo se centra en «lo comunicado», es decir, en la realidad que se comunica y en su significado propio, esto es, en su contexto significativo.

En esta línea, el profesor Navarro Colorado (2003) señala que

...todo comunicado es, por definición, multimedial, ya que está compuesto por más de un medium, es decir, por signos pertenecientes a más de un sistema semiótico [...]. [E]l comunicado forma un complejo sígnico relacional formado por cuatro componentes básicos: el vehiculum, o la manifestación física del comunicado; la formatio, o arquitectónica formal del comunicado; el sensus, o arquitectónica semántica del comunicado; el relatum, o realidad extratextual expresada en el comunicado (5-6).

Tanto el sensus o «arquitectónica semántica», así como en el relatum, es decir la «realidad extratextual»-el contexto significativo-, constituyen el enfoque que fundamenta este estudio; es decir, la realidad familiar que ha de ser comunicada en el contexto de la comprensión de la familia desde una perspectiva de crisis.

\section{La familia como problema y la no armonía varón-mujer como causa}

La etiología de esta crisis es compleja y de difícil síntesis; en todo caso, parece claro que la ruptura de los lazos matrimoniales -dificultades para establecer 
vínculos estables- se muestra como una de las causas de esta situación.

También parece causa de crisis la identificación de la institución familiar -de su naturaleza- con las diversas situaciones por las que atraviesa, ligadas a circunstancias contingentes, de suerte que se sitúan en el mismo plano la naturaleza de la institución y las coyunturas en las que pueden encontrarse algunas familias: por ejemplo, que falte uno de los cónyuges. Se deja de hablar de la naturaleza de la institución familiar qué es en sí la familia-y se sustituye por un discurso en torno a los «tipos de familias», incluyendo entre ellas a la «familia tradicional». De este modo, notas que corresponden a la naturaleza pasan a formar parte de un abanico de posibilidades o incluso llegan a considerarse como parte de la estructura «antigua» de la forma familiar. Estamos, sin duda, en un contexto de índole nominalista, en el que la identidad propia de la institución familiar no tiene espacio en el discurso ni recursos intelectuales para ser pensada.

Por último, otro elemento que ha incidido en la crisis de la institución y que será nuestro objeto de estudio es la falta de armonía en las relaciones varón-mujer, la comprensión de las mismas como antagonismo dialéctico, en términos de poder (Sáez, Valor-Segura y Expósito, 2012).

En torno a la realidad familiar se abre un doble discurso: por un lado, el de la valoración mayoritaria que de ella se hace -al menos en España y en América Latina- y por otro, las reflexiones que, desde los años 50, influyen en la configuración de cierto ideario común y en el discurso de muchos medios de comunicación, en ámbitos de opinión, en espacios académicos. Así, una agencia de noticias, con motivo del Día Internacional de la Familia, señalaba que la institución familiar es la más valorada por los ciudadanos y la más olvidada por los políticos (Europa Press, 2011). Sin embargo, en la actualidad informativa que transmiten los medios de comunicación, la familia aparece, en muchas ocasiones, como algo problemático: no siempre es un espacio de convivencia deseable, no siempre las relaciones entre sus miembros manifiestan una realidad solidaria donde cada uno es «amado por sí mismo» (Schumacher, 2012), o donde sus miembros están cohesionados por el amor personal que se tienen unos a otros (De Irala, 2016).

Un ejemplo claro de esto es el lugar tan destacado que ocupa la violencia doméstica que, sin dejar de ser un problema al que debe prestarse la mayor atención, parece ser, en los medios, «la» imagen más notoria referida a la familia. Sin duda el impacto de este tipo de noticias, su cantidad y cualidad, han sido ampliamente estudiados (Roselló, 2009).

Así, es común que, a partir de la influencia de los medios de comunicación, se entienda a la familia como origen de conflictos, o como estructura de índole exclusivamente cultural de la que, especialmente la mujer, ha de liberarse (Herrera, 2009). La «emancipación» sigue siendo un ideal arraigado desde la Ilustración -visto de modo 
muy claro en el ambiente exasperado de mayo de 1968 (Saranyana, 2011)-, no entendida como capacidad, por ejemplo, de sostenerse económicamente o tener un proyecto de vida personal, sino como desvinculación, como rompimiento de vínculos estables. Este ideal de emancipación, por otra parte, contiene serias implicaciones antropológicas. En este sentido, encontramos dos perspectivas antitéticas: por una parte, la propuesta por Kant en ¿Qué es ilustración?

La Ilustración es la salida del hombre de su autoculpable minoría de edad. Minoría de edad significa la incapacidad de servirse de su propio entendimiento sin la guía del otro. Uno mismo es culpable de esta minoría de edad cuando la causa de ella no reside en la carencia de entendimiento, sino en la falta de decisión y valor para servirse por sí mismo de él sin la guía de otro iSapere aude! (1979: 35).

Frente a esto, en Ayudar a crecer escribe Leonardo Polo que

Darse cuenta o no de que se es hijo no es indiferente. Ni se puede prescindir de esto ni olvidarlo; porque insisto- si el hijo no es un ex-hijo nunca, sino que es hijo permanentemente, no tiene sentido olvidarse de ello. Sin embargo, se puede decir que en nuestros días el hombre no quiere ser hijo. La conciencia de filiación se ha debilitado, e incluso el hombre se ha rebelado contra su condición de hijo, porque quiere debérselo todo a sí mismo (2006: 44).

Si la familia implica el establecimiento de relaciones como la maternidad, la paternidad o la conyugalidad matrimonial -lazo estable entre varón y mujer-, es claro que los movimientos feministas y de género ven en la estructura familiar un problema para la libertad: la mujer ha de «liberarse» de ella. Como señaló Simone de Beauvoir (2005) a mediados del siglo XX, se trata de una liberación de las relaciones que han definido a la mujer durante siglos -hija de, esposa de, madre de-, relaciones todas ellas de carácter intrafamiliar, con la consiguiente desvalorización de la maternidad (Martínez, 2011).

En ese proceso de liberación, poco a poco ha tomado fuerza el término «empoderamiento»-Paolo Freire lo divulga en el enfoque de «educación popular» de los años 60- (Murguialday, Pérez de Armiño y Elzaguirre, 2006), que se consolida en los discursos en torno al «género» especialmente a partir de la "Declaración y Plataforma de acción de Beijing" (Naciones Unidas, 1995). En la actualidad el campo de aplicación del término es plural. Puede entenderse como "el aumento en la capacidad de las mujeres para ampliar sus opciones de vida y tomar sus propias decisiones" (Pérez Villar y Vázquez García, 2009: 187); aunque asímismo

...se utiliza en el contexto de la ayuda al desarrollo económico y social para hacer referencia a la necesidad de que las personas objeto de la acción de desarrollo se fortalezcan en su capacidad de controlar su propia vida. También puede ser interpretado el empoderamiento como un proceso político en el que se garantizan los 
derechos humanos y justicia social a un grupo marginado de la sociedad (VV.AA., s.f.).

Por otra parte, visto por grupos de mujeres o movimientos sociales, el empoderamiento es "una estrategia que propicia que las mujeres, y otros grupos marginados, incrementen su poder, esto es, que accedan al uso y control de los recursos materiales y simbólicos, ganen influencia y participen en el cambio social" (Murguialday et al., 2006).

Además está la visión más radical de quienes "cuestionan directamente los patrones de poder existentes" (VV.AA., s.f.) y subrayan que en el empoderamiento de las mujeres no se trata de sustituir una forma de empoderamiento con otro:

El empoderamiento de las mujeres debe conducir a la liberación de los hombres de falsos sistemas de valores e ideologías de opresión. Esto ha de llevar a una situación en la que cada uno pueda convertirse en un ser completo sin importar el género, y pueda usar todo su potencial para construir una sociedad más humana para todos² (Oxaal y Baden, 1997: 2).

Así las cosas, si las relaciones intrafamiliares son un obstáculo para el desarrollo de la persona -en el contexto heredero de la Ilustración-, es claro que, en gran medida, la familia es una institución problemática y esto apunta a las relaciones varón-mujer como uno de los elementos de mayor fricción. En de- finitiva, la «armonía» como ideal de relación y convivencia ha desaparecido del horizonte, sustituida por las relaciones de poder (Portillo, 2011) y empoderamiento. Se establece la disyuntiva «armonía» versus «luchas de poder».

En este último paradigma, la relación varón-mujer es origen de conflicto, por lo que la solución tiende a pensarse en término de eliminación de la diferencia -puesto que se confunde con desigualdad en los derechos-, ya sea porque se pretende una identificación de los roles femeninos y masculinos, ya sea porque se incluye lo femenino en marcos conceptuales ideológicamente radicalizados. En los dos casos, la especificidad de la mujer y del varón, parece perderse. Y no sólo esto: nos encontramos en pleno siglo XXI con que muchos varones han perdido su identidad en una sociedad feminizante (Calvo, 2011; Romero Iribas, Martínez Priego, 2017).

Y si no se muestra claramente la especificidad -dentro de una igual dignidad-, la correspondencia, que es condición de armonía, queda imposibilitada. Es decir, que si se anula la diferencia varón-mujer, no es posible esta armonía.

$\mathrm{Al}$ acercarnos a la palabra «armonía», por otro lado, podemos destacar dos acepciones: "Conveniente proporción y correspondencia de unas cosas con otras" o "Amistad y buena correspondencia" (Real Academia Española, 2011) que, en último término muestran la acción misma o el efecto de «corresponder», lo cual

2 La traducción al español es nuestra. 
da a las partes implicadas carácter activo. Cuando hablamos de armonía, por tanto, no nos referimos a la prevalencia o primacía de ninguno de los dos -varón o mujer-, sino a la adecuada respuesta de uno al otro por lo que se subraya ese carácter activo de cada uno de los miembros armónicamente relacionados. La armonía no implica, propiamente, jerarquía.

En la reflexión en torno a la familia, pasar del ámbito en el que la persona es querida por sí misma hasta las luchas de poder, supone un "corrimiento» conceptual, que resulta de una confusión entre el ámbito intrafamiliar y extrafamiliar, cuyas lógicas no son en absoluto homogéneas pues "un conjunto de familias no es una familia" (Polo, 2005: 75). En efecto, como ha descrito acertadamente este autor, la consistencia familiar es muy superior a la social. Esta última depende íntegramente de la ética y está abierta a múltiples posibilidades, lo que no sucede con la familia cuya estructura originaria no depende del arbitrio humano. Es la familia el origen del vínculo social y no al revés (De Irala, 2016).

Ahora bien, ¿cómo comprender la alteridad en términos distintos a los planteados? ¿Puede la realidad humana ser comprendida desde un paradigma diverso al dialéctico? ¿Son las relaciones de poder las únicas que permiten explicar los dinamismos intrafamiliares?

\section{La armonía varón-mujer: una apro- ximación sistémica}

El planteamiento de tipo analítico y homogeneizador de las relaciones in- trafamiliares y extrafamiliares, tiene importantes limitaciones para abordar las cuestiones humanas. Es decir, el pensamiento que busca la claridad, la distinción y la economía, no es adecuado porque en el ámbito humano -ya sea en la consideración de la persona o bien de la realidad social-, todo tiene que ver con todo: la simplificación, la eliminación de elementos so capa de esa claridad y distinción, hace que se pierdan elementos pertinentes. Por eso, proponemos la consideración sistémica (Polo, 2005): en ella, los diversos elementos que componen una realidad han de verse en cuanto se iluminan unos a otros en su sentido.

Pues bien, es común tratar algunas características que posee la relación intrafamiliar de la mujer y el varón, pero no es habitual estudiarlas en su relación interna: abordarlas en un mismo estudio para tratar de comprender su significado en la ligazón mutua.

Como marco general, hemos de explicitar que la familia considerada como realidad viva, a nuestro juicio, ha de entenderse desde la persona, de suerte que parece necesario afirmar que «la persona es originariamente familiar» (Martínez Priego, 2016). Es decir, que no es posible existir al margen de las relaciones interpersonales primarias «específicas»: filiación, maternidad-paternidad y como condición de todas ellas, la conyugalidad.

No hablaremos propiamente del matrimonio -lazo, alianza, unión de varón y mujer- sino de la realidad social que conforma un peculiarísimo núcleo de personas por el que y en el que nacemos. 
El centro de la vida familiar es la posibilidad del advenimiento de la persona, de una persona nueva.

Si lo más importante siempre y en toda circunstancia es la persona, en tal caso la familia tiene una relevancia singular dentro de las instituciones o realidades surgidas de las relaciones interpersonales primarias, puesto que es el lugar en el que ésta, la persona, nace; es el espacio en el que es posible el surgimiento natural de la novedad radical que supone cada persona. La familia es condición de posibilidad de la persona nueva (Martínez Priego, 2016: 25).

En este contexto, la relación varónmujer, vista desde la conyugalidad -que es el principio cronológico de la vida familiar no el principio como causa final-, podría ser entendida según tres rasgos: la reciprocidad -en orden al amor-; la complementariedad -en orden a la persona nueva-; y la co-responsabilidad -en orden a la tarea-. Este es el planteamiento que proponemos.

\subsection{Reciprocidad}

El dinamismo familiar interno está fundado en un tipo de relaciones primarias caracterizadas por la donación y la aceptación, esto es, por el «amor personal» (Martínez Priego, 2011). Si se habla de amores personales, no se trata de relaciones meramente biológicas, sino de vínculos llamados a plenitud, precisamente, en cuanto designan amores personales -ligadas por lo mismo a la libertad personal-. En este sentido, varón y mujer están llamados a vivir una comunidad de amor (Instituto de Política
Familiar, 2008). La familia supone "una dimensión de la persona, un modo suyo de ser: el modo más inmediato en el que se manifiesta que la persona existe para la comunión” (Buttiglione, 1994: 7).

Cuando hablamos de «amor personal», estamos designando algo distinto a los amores descritos por C.S. Lewis (2000). Si nos situamos en el contexto del amor personal, hemos de mirar al «amor originario", el que nos puso en la existencia. El amor primero es el que funda la alegría primera, es decir, aquella que procede del saberse querido. Es en virtud de ese querer originario como se conoce la bondad de la propia existencia y la bondad del mundo que es el lugar donde poder desarrollar la propia vida (Rof Carballo, 1987). Esto lo han afirmado numerosos autores: desde Spitz a Rof Carballo, pasando por Melani Klein o Winnicott. Por otro lado, en el amor originario "el referente es [...] la persona y consiste en la afirmación total de la bondad de la existencia del otro" (Martínez Priego, 2016: 56). Si el amor conyugal es «amor personal», tiene esta misma nota distintiva: consiste en la afirmación total de la bondad de la existencia del otro. $\mathrm{Si}$ hemos sido amados de este modo que implica totalidad y exclusividad, podemos también amar de este modo.

Sin embargo, el único amor no es el originario recibido. En efecto, "hay un amor recibido y hay un amor buscado. Hay un recibir originario y un dar-darseposible. Aquí nace la reciprocidad. Si hemos sido amados así, podremos amar del mismo modo" (Martínez Priego, 2016: 57), como se ha dicho. En definitiva, la condición de la reciprocidad es 
la lógica del «don-aceptación» y ésta no corresponde primariamente ni a la mujer ni al varón, sino a ambos en cuanto son don uno para el otro y han de aceptarse mutuamente. En el origen de la existencia personal existe un querer que «recibido» se ha de hacer «don» que se entrega al otro. Si la primera nota del amor personal conyugal es la reciprocidad, las relaciones interpersonales han de estar regidas por la gratuidad, la donación y el servicio (Margenat Peralta, 2013).

\subsection{Complementariedad}

Señalamos que la familia se entiende desde la persona. Puesto que nadie se da a sí mismo la existencia, «ser persona» $\mathrm{y}$ «ser hijo» son indisociables (Polo, 1995). Ahora bien, si hay hijo hay filiación y con ella paternidad y maternidad. Por esto hemos afirmado que la complementariedad se da en orden a la persona nueva. Y esto es evidente puesto que se trata de conceptos denominados clásicamente «opuestos relativos»: si se da uno ha de darse el otro.

Precisamente por eso, la persona no se entiende al margen de la complementariedad varón-mujer que es el principio de toda existencia. En el seno de la familia, la diferencia sexual no es un elemento más, un rasgo más de las personas, sino que se destaca como una realidad esencial. De este modo, sexualidad, familia y carácter filial de la persona humana, son realidades que se iluminan mutuamente.

La complementariedad se manifiesta en múltiples esferas: corporal, psíquica, cultural y social. Es característica su capa- cidad de mostrar la noción de diferencia -entendida en nuestro caso como elemento positivo, no como desigualdad-y la unidad armónica de lo diverso. Sin duda, esta es una nota que ha sido abundantemente estudiada en los campos de la antropología y la teología (Castilla, 2004; Araujo, 2005; Aparisi, 2006).

Así como hemos señalado que en virtud de la reciprocidad la familia es comunión de amor, puede decirse que, en virtud de la complementariedad, es santuario de la vida.

\subsection{Co-responsabilidad}

Ahora bien, hay otro concepto que, entendemos, posee la virtualidad de mostrar esa unidad en la dimensión proyectiva del matrimonio para la conformación de la realidad familiar: nos referimos al término co-responsabilidad (Elósegui, 2002). En efecto, la diversidad de roles -más estables unos, más circunstanciales otros-, no desliga a ninguno de los dos, ni al varón ni a la mujer, del contenido total de su proyecto común.

Comentaremos dos ámbitos en los que la co-responsabilidad es clave: el ámbito educativo y el del sostenimiento del hogar que conduce a la armonización entre la vida laboral y familiar, o el trabajo fuera y dentro de casa en otras ocasiones.

Obviamente, el lugar propio y primero de la co-responsabilidad, la tarea que en primer término exige la contribución paterna y materna, es la crianza y educación de los hijos. Pues

...las características del ser originado del hombre -todo hombre es hijoapuntan no sólo a la procreación, sino 
también a la ayuda y cuidados que permitan la supervivencia biológica tras el nacimiento -crianza-y más allá de ella la humanización, es decir, la educación (Martínez Priego, 2014: 6). Aunque procreación, crianza y educación constituyen un único proceso en orden al logro de la plenitud humana, es especialmente por la tarea educativa donde el hombre y la mujer pueden llamarse propiamente padre o madre. En algunos lugares, sin embargo, aún es común que la responsabilidad en este punto recaiga más o exclusivamente sobre la mujer. En el ámbito educativo, en ocasiones, el padre es alguien ausente.

Por otra parte, habitualmente, cuando se plantea la cuestión de la igualdad y diferencia de sexos en el desarrollo de la vida familiar, surge la cuestión de la dimensión profesional de cada uno de ellos. En ese momento, comienzan las dificultades reales referidas a la armonía de vida familiar y profesional. Algunos estudios recientes en relación al feminismo afirman que alguna de las causas de la radicalización en torno al abandono de las tareas del hogar por parte de la mujer, es una reacción justificada frente al abandono del hogar por parte del hombre, más que un rechazo por parte de ellas al hogar. Coresponsabilidad, por tanto, comporta también que el varón descubra que es misión suya cuidar de la casa y de la familia, que es responsable de ser esposo y padre. Para el varón, el hogar es cosa fundamental

...y apartarlo de esta función sería un notable empobrecimiento de su personalidad masculina (...) Considerar que sólo es misión de la mujer cuidar del hogar sería mal comprender el fondo del asunto, como también lo sería pensar que la mujer, para librarse de una tutela patriarcal obsesiva e injusta, debe romper todos sus vínculos con el hogar (Saranyana, 2011).

Por lo dicho no se concluye que la mujer sea la responsable del sostenimiento de la familia «hacia dentro»-la crianza y educación de los hijos- y el padre, el varón, «hacia fuera», responsable de la obtención de recursos económicos para el sustento. Salvo algunas funciones no intercambiables -la maternidad misma o la lactancia y sus implicaciones, por ejemplo- no parece que la condición sexuada lleve consigo una distribución de tareas determinada «por naturaleza». Lo que sí podría afirmarse es que la solución a este grave dilema de la armonía trabajo familiar y profesional, puede estar en el reto de "construir una sociedad con madre y una familia con padre" (Aparisi, 2011: 18).

\section{El carácter sistémico de la recipro- cidad, complementariedad y co-res- ponsabilidad}

Las dificultades para comprender la armonía varón-mujer, según hemos ido señalando, se sitúan en dos lugares: la lógica del poder introducida en el seno de las relaciones intrafamiliares y la visión analítica de la realidad familiar.

Frente a ellas proponemos la dinámica donación-aceptación que caracterizan el «amor personal»y por tanto el principio de gratuidad como régimen de las relaciones intrafamiliares, 
así como la visión sistémica de las notas esenciales que caracterizan la relación varón-mujer en el seno de la vida familiar. Ahora bien, puesto que la consideración analítica de los elementos señalados no permite destacar adecuadamente su sentido, ¿de qué modo quedan iluminadas estas tres notas?

Conviene para ello atender a algunas consideraciones. Por un lado, existe una cierta implicación mutua entre los tres elementos que definen la relación varón-mujer en el seno de la vida familiar y los amores personales. De hecho, es en ese contexto como pueden entenderse estos elementos o notas de la relación. No son relaciones de poder sino de donación-aceptación. Además, en cuanto amores personales, lo son de totalidad y exclusividad. De hecho, así se describe el amor primero -el de carácter filial- y también los otros amores personales que describen las relaciones interpersonales primarias propias de la familia: maternidad-paternidad -que tienen como condición la conyugalidad-. Pues bien, el amor primero -el recibido- hace posible el "darse mutuo», donde nace la reciprocidad.

Ahora bien, si el centro de la vida familiar es la «posibilidad del advenimiento de la persona nueva», esto solo es posible desde la complementariedad varón-mujer. Pero tal complementariedad -segunda nota- no sería plena si se tratase de un mero acontecimiento biológico. Es decir, exige el encuentro personal y la donación-aceptación mutuas, lo que apunta a la reciprocidad -primera nota descrita-. Además, puesto que el sostenimiento de la persona nueva -por las características mismas del niño, del hijo, su inviabilidad biológica al margen del cuidado tutelar- exige una atención prolongada en el tiempo, el centro de la vida familiar es, de suyo, de carácter proyectivo. No es viable la condición materno-paterna al margen del proyecto común y no es posible la consideración de la vida familiar sin convivencia y, por tanto, sin un espacio interior compartido: el hogar. De este modo, la coresponsabilidad tiene sentido ligada a la complementariedad y la reciprocidad.

Son co-resposables todos aquellos que inician una tarea común; pero en el seno de la vida familiar, la co-responsabilidad mujer-varón está ligada al contenido de su vida común de carácter complementario -en orden a la procreación- y recíproco -es de carácter amoroso, no solo «de facto» o biológico-. Por ser en orden a la procreación, tampoco es una mera unión de dos, absuelta de toda condición biológico-natural. Lo natural llega a plenitud libremente, como la complementariedad sexual en el seno de la conyugalidad llega a plenitud en la reciprocidad.

$\mathrm{Al}$ situar el centro de la vida familiar en «la posibilidad del advenimiento de la persona nueva» podría parecer que ponemos frente a frente a quienes priorizan el matrimonio o la vinculación libre por un lado, y a quienes otorgan el mayor peso a los hijos y con ello a la biología por otro (Carreras, 2008). En esa misma línea se sitúa Lévi-Straus (1987) cuando habla de dos sectas rivales. 
Como venimos señalando, la principal objeción que puede hacerse a este planteamiento es, precisamente, el carácter excluyente que se da a los elementos. En la realidad, se trata de dos elementos solidarios, co-implicados. La clave para la comprensión de la realidad familiar radica en la naturaleza de las relaciones establecidas entre personas: relaciones de carácter personal que hemos venido llamando conyugales -de tipo esponsal por tanto- como condición y fundamento de las filiales y materno-paternas (Donati, 2003).

Se puede añadir, sin embargo, otra muestra del carácter solidario de las dimensiones citadas; en concreto, la lógica donación-aceptación se realiza primariamente en el hijo respecto a los padres, como acaece entre los esposos entre sí. Donación-aceptación, referida tanto al hijo como a los padres entre sí, hace que la familia pueda llamarse «comunidad de amor»y «santuario de la vida». De este modo, toda consideración biologicista -prima la procreacióno espiritualista -prima la libertad de la pareja-, aparece como reductiva y desconocedora de la plenitud de las relaciones interpersonales. En el ser humano, relación interpersonal implica lo biológico y lo libre, lo íntimo y lo manifiesto. En último término se trata de mostrar que la vida conyugal no es un mero acontecimiento biológico, sino un «encuentro personal» (Cafarra, 1987). De ahí que la sexualidad humana sea distinta a la no humana, puesto que la primera es manifestativa de la persona, de su intimidad y capacidad de hacer de sí un don para el otro. Tampoco los hijos son un mero acontecimiento biológico, como pone en evidencia el hecho de que la plenitud de la paternidad acontece en la educación (Millán Puelles, 1983). En efecto, si los hijos no fueran don sino sólo un «producto» de la relación sexual, estaríamos omitiendo su carácter personal, de suerte que los padres podrían considerarlo «derecho» o "propiedad». En la misma medida en que el hijo es don, se subraya la libertad y el carácter personal del hijo (Sellés, 2006). El hijo es originariamente libre.

La conyugalidad -esencia de las relaciones matrimoniales- es, por tanto, fundamento de la vida familiar en cuanto supone la primera donaciónaceptación personal y principio de la novedad que es la persona. La sexualidad humana aparece, así, con toda su riqueza. Se supera también toda posibilidad de ver la sexualidad como un mero acontecer biológico, o como una determinación libre «descarnada» o «clausurada» en la subjetividad, separada de la dinámica corporal manifestativa de la dignidad humana. Es por eso por lo que el matrimonio exige, para su plenitud, la entrega corporal y la apertura a la vida.

\section{A modo de conclusión: familia y co- municación de la realidad familiar}

Comunicar es participar, tomar parte, y aquello de lo que se ha de tomar parte es el significado de la realidad. Este ha sido el objetivo de nuestro estudio: centrar la atención en «lo comunicado», es decir en la realidad que se comunica y su significado propio. Hemos expuesto 
una aproximación al contenido significativo de la relación varón-mujer en el seno de la vida familiar, atendiendo a la metodología propuesta: la necesidad de considerar sistémicamente -no analíticamente- las realidades humanas.

Pues bien, lo comunicado, al ser considerado sistémicamente, permite superar la visión crítica -de institución en crisisque suele ofrecerse de la familia en muchos casos. Ésta procede de la confusión y homogenización de las relaciones intra y extra familiares, de la inclusión de las relaciones de poder en el vínculo varónmujer en el seno del matrimonio.
Lo comunicado se ajustaría más a la realidad si se tuviera en cuenta el vínculo mujer-varón en su completitud, es decir, en la mutua relación de las tres notas propuestas: reciprocidad, complementariedad y co-responsabilidad. Así, atendemos a la lógica de la gratuidad -donación-aceptación-, la primacía de la persona nueva -el hijo- y su carácter proyectivo. Entendemos que cuando se olvida alguno de estos pilares, no puede darse una visión completa de la familia, lo que dificulta la comunicación adecuada de la realidad familiar.

\section{Referencias Bibliográficas}

Aparisi, A. (2006). La complementariedad varón-mujer en la familia y en la sociedad. Nuestro Tiempo, núm. 627, 105-109.

Aparisi, A. (2011). Prólogo. En: M. Miranda y D. López (Eds.). Ideología de Género (Vol. 1). Costa Rica: Universidad de Navarra y Promesa, 11-18. Araujo, A. (2005). Complementariedad varón y mujer. Persona y Bioética, vol. 9 (1), 78-85. Buttiglione, R. (1994). El hombre y la familia. México: IMDOSOC.

Cafarra, C. (1987). La sexualidad humana. Madrid: Encuentro.

Calvo, M. (2011). La masculinidad robada. Madrid: Almuzara.

Carreras, J. (2008). Soberanía Conyugal. Madrid: Lulu.

Castilla, B. (2004). La complementariedad varón-mujer. Nuevas hipótesis (3 ${ }^{\underline{a}}$ ed.). Pamplona: Documentos del Instituto de Ciencias para la Familia.

De Beauvoir, S. (2005). El segundo sexo. Madrid: Cátedra.

De Irala, J. (2016). La familia, raíz de la esperanza. Ponencia. Congreso de la Familia (22-23 febrero). Universidad Panamericana, Campus Guadalajara, México.

Donati, P. (2003). Manual de Sociología de la Familia. Pamplona: Eunsa.

Recuperado de http://www.europapress.es/epsocial/familia-00324/noticia-familia-institucionmas-valorada-espanoles-mas-ninguneada-politicos-asociaciones-20110514133013.html

Elósegui, M. (2002). Diez temas de género. Hombre y mujer ante los derechos productivos y reproductivos. Ediciones Internacionales Universitarias: Madrid.

Herrera, M. (2009). Análisis psicosocial de a violencia de género: sexismo, poder y amenza como factores explicativos. (Tesis doctoral).Universidad de Granada, Granada, España. Recuperado de http://0-hera.ugr.es.adrastea.ugr.es/tesisugr/18509769.pdf

Instituto de Política Familiar (2008). Informe de la evolución de la familia en Europa. Recuperado de http://www.ipfe.org/Espa\%C3\%Bla/Documento/35 
Kant, E. (1979). Filosofía de la Historia. México: Fondo de Cultura Económica.

Lévi-Straus, C. (1987). Prefazione. En: AA.VV. Storia Universale della Famiglia. Milano: Mondadori.

Lewis, C. (2000). Los cuatro amores. Madrid: Rialp.

Margenat Peralta, J.M. (2013). Una nueva síntesis humanista para un orden económico y social justo. Revista de Fomento Social, vol. 68, 50-70.

Martínez, C. (2011). Conciliación de la vida familiar y laboral, feminismo y políticas sociales. En: M. Miranda y D. López (eds.). Ideología de Género (Vol. 1). Costa Rica: Universidad de Navarra y Promesa, 365-377.

Martínez Priego, C. (2011). Los amores personales. Conferencia, Centro Universitario Villanueva, Universidad Complutense de Madrid, Madrid.

Martínez Priego, C. (2014). Dinamismo familiar interno. I Simposium World Youth AllianceSpain, Centro Universitario Villanueva, Universidad Complutense de Madrid, España.

Martínez Priego, C. (2016). Dinamismo familiar interno. En: C. Martínez Priego y M. Rumayor (Eds.). La familia y sus ámbitos. Cinco ensayos en torno a la familia desde la persona. México: Porrúa, 25-58.

Millán Puelles, A. (1983). La formación de la personalidad humana. Madrid: Rialp.

Murguialday, C., Pérez de Armiño, K. y Elzaguirre, M. (2006). Empodemariento. En: Diccionario de Acción Humanitaria y Cooperación al Desarrollo. Recuperado de http://www.dicc. hegoa.ehu.es/listar/mostrar/86

Naciones Unidas. (1995). Declaración y Plataforma de acción de Beijing. UN Women: United Nations. Recuperado de http://beijing20.unwomen.org/ /media/headquarters/attachments/sections/csw/bpa_s_final_web.pdf

Navarro Colorado, B. (2003). Aspectos retórico-comunicativos del desarrollo de sitios web. En: International Society for the History of Rhetoric. XIV Biennial Conference. Madrid y Calahorra. Recuperado de http://www.dlsi.ua.es/ borja/ishr03.pdf

Oxaal, Z., y Baden, S. (octubre de 1997). Gender and empowerment: definitions, approaches and implications for policy. Bridge. Development-Gender. Recuperado de http://www.bridge. ids.ac.uk/reports/re40c.pdf

Paz García, A. y Brussino, S. (2015). Perfiles ideológicos del consumo mediático de información política en Córdoba-Argentina. Anagramas, Vol. 12 (24), 95-118.

Pérez Villar, M., y Vázquez García, V. (2009). Familia y empoderamiento femenino: ingresos, trabajo doméstico y libertad de movimiento de mujeres chontales de Nacajuca, Tabasco. Convergencia. Revista de Ciencias Sociales, vol. 50, 187-218.

Polo, L. (1995). El hombre como hijo. En: J. Cruz Cruz (Ed.), Metafísica de la familia. Pamplona: Eunsa, 317-325.

Polo, L. (2005). Quién es el hombre. Un espíritu en el tiempo. Madrid: Rialp.

Polo, L. (2006). Ayudar a crecer. Cuestiones filosóficas de la educación. Pamplona: Eunsa.

Portillo, J. (2011). Consecuencias de las leyes promulgadas con perspectias de género en España. En: M. Miranda y D. López (Eds.), Ideología de Género (vol. 2). Costa Rica: Universidad de Navarra y Promesa, 245-265. 
Real Academia Española. (2011). Armonía. En: Diccionario de la Lengua Española. Recuperado de http://lema.rae.es/drae/?val=armon\%C3\%Ada

Redondo, E. (1999). Educación y comunicación. Barcelona: Ariel.

Rof Carballo, J. (1987). Violencia y Ternura. Madrid: Austral.

Romero Iribas, A. y Martínez Priego, C. (2017). Topografía de las relaciones

interpersonales en la postmodernidad: amistad y educación. Revista Española

de Pedagogía, 75(267), 309-322.

Roselló, E. (2009). La violencia de género en los medios de comunicación, (Tesis doctoral). Universidad de Alicante, Alicante, España.

Sáez, G., Valor-Segura, I., y Expósito, F. (2012). ¿Empoderamiento o Subyugación de la Mujer? Experiencias de Cosificación Sexual Interpersonal. Psychosocial Intervention, vol. 21(1), 41-51.

Saranyana, J. (17 de febrero de 2011). Sobre la condición femenina de nuestro tiempo. Recuperado de http://www.temesdavui.cat/es/revista/38/estudios/sobre_la_condicion_femenina_en_nuestro_tiempo

Schumacher, M. (2012). Feminismo, Naturaleza y Humanae Vitae. Estudios, vol. 101 (10), 8-33.

Sellés, J. (2006). Filiación personal humana. Estudio acerca de lo si lo más radical de la antropología es ser hijo. Cauriensia, vol. 1, 201-217.

Vilanova, N. (2012, octubre 18). Comunicar es contar historias. Recuperado de http://www. nuriavilanova.com/2012/10/18/comunicar-es-contar-historias/

VV.AA. (s.f.) Empoderamiento. En: Diccionario de Ciencias Sociales de la Universidad de Málaga. Recuperado de http://www.eumed.net/cursecon/dic/oc/empoderamiento.html 